\title{
The effects of ecolabels on environmentally- and health-friendly cars: an online survey and two experimental studies
}

\author{
Frans Folkvord ${ }^{1,2,3,4}$ (D) Giuseppe A. Veltri ${ }^{5}$ - Francisco Lupiáñez-Villanueva ${ }^{6}$ - Pietro Tornese $^{7}$. \\ Cristiano Codagnone $^{6,8} \cdot$ George Gaskell $^{9}$
}

Received: 15 June 2018 / Accepted: 28 May 2019 / Published online: 1 July 2019

(C) The Author(s) 2019

\begin{abstract}
Purpose Given the increasing importance of political decision-making to reduce emission targets, the main purpose of the current paper is to identify and test the considerations that would nudge consumers towards an environmentally and health-friendly motor vehicle. Methods An online survey was conducted to assess public responses and the role of public authorities to a voluntary emission standard for passenger cars. In addition, two online experiments were conducted to test incentives in the design of ecolabels (e.g. price, safety, performance) for optimization. A random sample of 6400 individuals was drawn from eight countries: Germany, Ireland, Italy, the Netherlands, Spain, UK, Czech Republic and Lithuania. An online survey was conducted among 3200 respondents, 400 in each of the 8 countries, and 2 online experiments with 3200 subjects, 400 in each of the 8 countries, allowing for 200 respondents for each experiment in each country.

Results and discussion The survey shows that Europeans are aware of the health and environmental impact of cars. The findings also confirm the gap between self-reported attitudes/intentions and actual behaviours. In influencing car purchase decisions, health and environmental concerns are less important than other attributes such as price, safety and performance. The experiments show that all these attributes have a significant effect on consumers' choices. However, message content was found to have the strongest effect. Respondents are more likely to choose European Union Low Emitting carS (EULES)-friendly cars when the label shows information on lower costs or lower taxes and less likely to be influenced by health-related benefits, convenient parking or access fees. Finally, combinations of one message with other elements - EULES logo, $\mathrm{CO}_{2} \operatorname{logo}$ or both-within the same label have a small but positive effect on respondents' choices.

Conclusions The findings of this study assist governmental decision-making processes by identifying those issues that have the greatest impact on consumers' car purchasing decisions. Furthermore, the results will help to guide environmentally conscious customers towards the purchase of vehicles with clean emission profiles.
\end{abstract}

Keywords Behavioural economics · Consumers' choice $\cdot$ Ecolabels $\cdot$ Environmental benefits $\cdot$ Experiment

Responsible editor: Fabio Iraldo

Electronic supplementary material The online version of this article (https://doi.org/10.1007/s11367-019-01644-4) contains supplementary material, which is available to authorized users.

Frans Folkvord

ffolkvord@open-evidence.com

1 Tilburg School of Humanities and Digital Sciences, Department Communication and Cognition Warandelaan 2, Dante Building, room D 4285037 AB, Tilburg, The Netherlands

2 Open Evidence Research, Universitat Oberta de Catalunya, Barcelona, Spain

3 Behavioral Science Institute, Radboud University, Nijmegen, The Netherlands
4 Communication Science, University of Amsterdam, Amsterdam, The Netherlands

5 Department of Sociology and Social Research, University of Trento, Trento, Italy

6 Department of Information and Communication Science, Open Evidence, Universitat Oberta de Catalunya, Barcelona, Spain

7 Open Evidence Research, Barcelona, Spain

8 Dipartimento di Scienze Sociali e Politiche, Universitá degli Studi di Milano, Milan, Italy

9 London School of Economics and Political Science, London, UK 


\section{Introduction}

The Paris Agreement, ratified globally by practically every country, except the USA and North Korea (UNFCCC 2018), states that economy-wide decisions should be introduced to achieve absolute emission reduction targets. Road transportation in Europe is a significant contributor to $\mathrm{CO}_{2}$ emissions, as well as air pollutants such as particulate matter and nitrogen oxides (EEA 2015; Davis et al. 2010). The greenhouse gas emissions from road transportation have significant impact on the environment and on human health (Woodcock et al. 2009). Furthermore, exposure to air pollutants has been identified as a significant risk factor in a number of health conditions including respiratory infections, heart disease, stroke and lung cancer (EEA 2015; WHO 2018). Greenhouse gas emissions still remain above agreed levels and would need to fall dramatically in order to meet international agreements (UNFCCC 2018). In order to comply with the directives of the Paris Agreement, European member states will be obliged to take green initiatives (e.g. fiscal incentives, local access restrictions for particular vehicles, local environmental zones differentiating vehicle access according to emission classes or ecolabels) to reduce air pollution in cities and highly trafficked areas (Kushwaha and Sharma 2016). Ecolabels are viewed as voluntary environmental and consumer policy instruments and taken to be a simple and pragmatic option.

Increasing concern about climate change has led to calls for labelling to allow consumers to differentiate between more or less sustainable purchasing options (Teisl et al. 2008). It is assumed that with appropriate labelling information, some consumers will be motivated to purchase cars that are more sustainable (Thøgersen et al. 2010). Ecolabelling is seen an important way of enhancing transparency and consumer trust in environmental claims. It is also viewed as a method for improving the sustainability of consumption patterns without compromising freedom of choice and at the same time reducing consumers' information search costs (Grunert and Wills 2007). The elaboration likelihood model (ELM; Petty and Cacioppo 1986) describes different ways of processing stimuli and how these affect outcomes, such as attitude change and eventually consumption behaviour. The ELM proposes two major routes that are used to process messages: the central and the peripheral routes. The central route involves an active consideration of the arguments presented in the message. By contrast, the peripheral route makes use of a simple heuristics about the merits of the advocated position, such as the credibility or attractiveness of the message. In the context of an ecolabel, the likelihood of elaboration with the central route is determined by an individual's motivation and ability to evaluate the information presented. With the purchase of a costly product such as a car, it is assumed that consumers will adopt the 'high-effort' central path (Thøgersen et al. 2010) in their assessment of ecolabels.
Importantly, Thøgersen et al. highlight the importance of constructs such as 'environmental involvement', the credibility of ecolabels and the extent to which consumers understand the information in choice behaviour (Bamberg 2003; Gadenne et al. 2011; Thøgersen 2000, 2002, 2005; Thøgersen et al. 2012; Thøgersen and Noblet 2012). For example, the credibility of labels can be influenced also by consumers' prior beliefs with regard to sustainable products (Teisl et al. 2003). The perceived effectiveness regarding their own behaviour and faith in the behaviour of others appear to be positively associated with increased effectiveness of labels as sources of information (Berger and Corbin 1992; Bougherara et al. 2005). As regards the labels as such, their effectiveness apparently increases when consumers can adequately rank competing products by key attributes (Teisl and Roe 2005), consumers' prior beliefs (Teisl 2003) or when consumers are educated about the presence and meaning of ecolabels (Song et al. 2019). Comparative labels are also considered a potentially effective way of rendering complex numerical information into simple categorical scales (Peters et al. 2009). However, the use of ecolabels has been criticised because they are based on the assumption that consumers and firms behave irrationally, such as the absence of evidence of an energyefficiency gap (Gayer and Viscusi 2013) and on the assumption that labels influence consumer to over-value energy consumption in the purchase of goods (Sahoo and Sawe 2015). Making use of ecolabels must therefore be based on robust evidence (Codagnone et al. 2016).

To encourage consumers to purchase less polluting vehicles, the European Commission is considering a voluntary emission standard, called European Union Low Emitting carS (EULES) with three complementary strategies (Ntziachristos et al. 2016): first, to promote clean transportation by providing a benchmark for local or national authorities in their development of financial or in green procurement projects; second, to provide an incentive for manufacturers to produce vehicles that deliver significant emission reductions; and third, by guiding environmentally conscious customers towards the purchase of vehicles with 'clean' emission profiles (low real-world driving emissions) by ecolabelling cars. The main focus of the present study is on this third strategy, the effect of ecolabelling cars.

Broadly defined ecolabelling is a signalling method to encourage future consumers towards forms of sustainable consumption (Thøgersen et al. 2010). In comparison to the more general literature on ecolabels, and especially to that focusing on white goods and food, studies examining the effects of car labelling are scarce, with a small number of scientific articles and a few policy reports (Choo and Mokhtarian 2004; Kurani and Turrentine 2002; Lane and Potter 2007; Loureiro et al. 2012; Noblet et al. 2006; Teisl et al. 2008; Teisl and Roe 2005). Therefore, it is necessary to establish which factors are associated with the effectiveness of labelling cars and to examine causal effects on consumption choices. 
To date, there is no single experimental study on the effect of car ecolabels on consumers' decision-making. Teisl et al. (2008) argue that rather than focusing on either the correlation between individual characteristics and environmental friendly behaviour (eco-behaviour) or between labels' characteristics and eco-behaviour, it is important to test a model linking individual characteristics and labels characteristics. They found that both label design and underlying psychological factors need to be taken into account. More specifically, if the label is well-designed, it can affect individuals' perceptions of the eco-friendliness of a product.

Findings concerning consumers' preferences and the car purchase process are reported by Achtnicht (2012), COWI (2002), Lane and Potter (2007), Noblet et al. (2006), Teisl et al. (2008), and Codagnone et al. (2013). These studies show that purchasing decisions are dominated by attributes such as price, performance and safety with eco-friendly attributes playing a secondary role. Secondly, the purchase of a car is found to be a two-stage process. Purchasers first determine the class of car they want to buy. It is only when they move to select the model that eco-friendly and fuel economy features are more seriously considered. Achtnicht (2012) finds that people in Germany say they are willing to pay more for a car that has lower $\mathrm{CO}^{2}$ emissions and that willingness to pay decreases for those who reported lower price ranges for a future car purchase and that differences were found by age, gender and educational level. Younger individuals, women and individuals with a higher education entrance qualification have a significantly higher willingness to pay.

Related with the debate in environmental behavioural economics is the legitimate question whether 'nudges' based on information supply differ from various forms of informational instruments (Kosters and Van der Heijden 2015). According to Ölander and Thøgersen (2014), ecolabels play the role of information provision at the point of sale but change the choice architecture of consumers when (if) consumers become familiar with and consider them as credible. Following the work of Peters et al. on label that performs well in summarizing complex numerical information (Peters et al. 2009), Johnson et al. (2012) consider 'good labels' (as opposed to bad ones) as an instrument of attribute parsimony to reduce attribute overload and as such they qualify them as a nudge for they alter the choice architecture. A further element for considering 'ecolabels' as a nudge is the evidence that their design affects consumers' perceptions (Heinzle and Wüstenhagen 2012).

In this study ${ }^{1}$, the main purpose is to identify and test the elements that would nudge consumers towards a preference for an environmentally and health-friendly EULES car. The

\footnotetext{
${ }^{1}$ This study is part of a larger study conducted for the European Commission (No. ENV.C.3/FRA/2013/0013, Service No. 8, EC DG ENV). The principal objective of the project was to provide the background on the potential of a voluntary low-emission standard for passenger cars in order to deliver realworld emission levels below the most stringent current emission limits, as well as to develop the technical and legal background for its implementation
}

study focusses on two separate objectives: first, mapping the contours of public responses and the role of public authorities to a voluntary emission standard for passenger cars that would deliver real-world emission levels below the current limits; second, experimentally testing the impact of different incentives designed to support the EULES policy. The outcomes of the research will:

1. Extend the knowledge base about car ecolabels.

2. Support governmental decision-making process on the successful introduction of the EULES labels.

3. Assess the differential impact on consumers' preferences between the $\mathrm{CO}_{2}$ label and the EULES label.

4. Help guide environmental conscious customers towards the purchase of vehicles with clean emission profiles.

5. Provide a benchmark for local or national authorities when developing financial or access and demand policies to promote clean transportation and to integrate footprint approaches into effective ecolabels.

\section{Methods}

To assess public responses to a voluntary emission standard for passenger cars, an online survey was conducted. In addition, two online experiments tested incentives for optimal message impact (see also Fig. 1). A random sample of 6400 individuals was drawn from 8 countries Germany, Ireland, Italy, the Netherlands, Spain, UK, Czech Republic and Lithuania. The sample was divided and allocated to (i) an online survey with 3200 respondents, 400 per each of the 8 countries, and (ii) two online experiments with 3200 respondents, 400 per each of the 8 countries, giving 200 respondents for each experiment and country. The randomization was ensured at the country level, such that each country was equally represented in the survey $(n=400)$ and

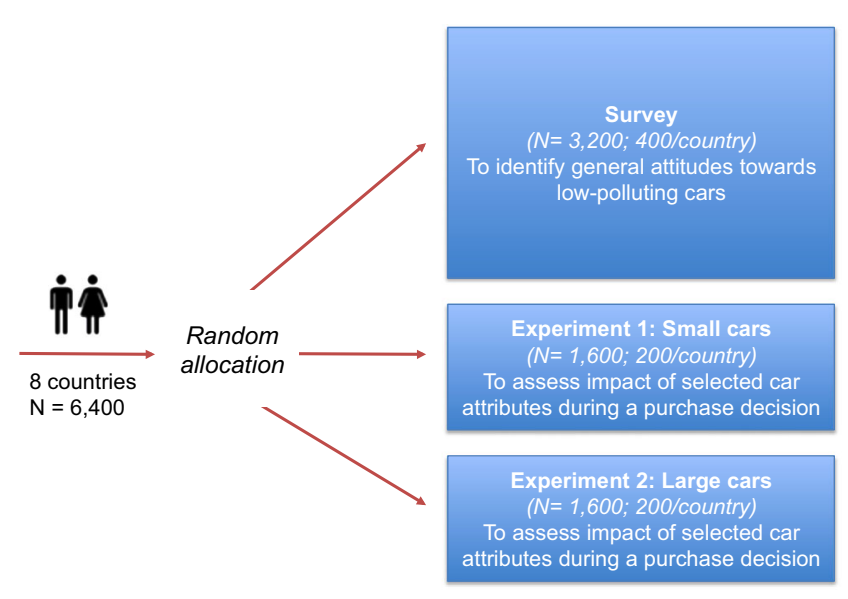

Fig. 1 Overview of the research design 
Fig. 2 Choice set no. 2 for small car
We would like you to consider the two cars presented below and their characteristics. Which car would you choose?
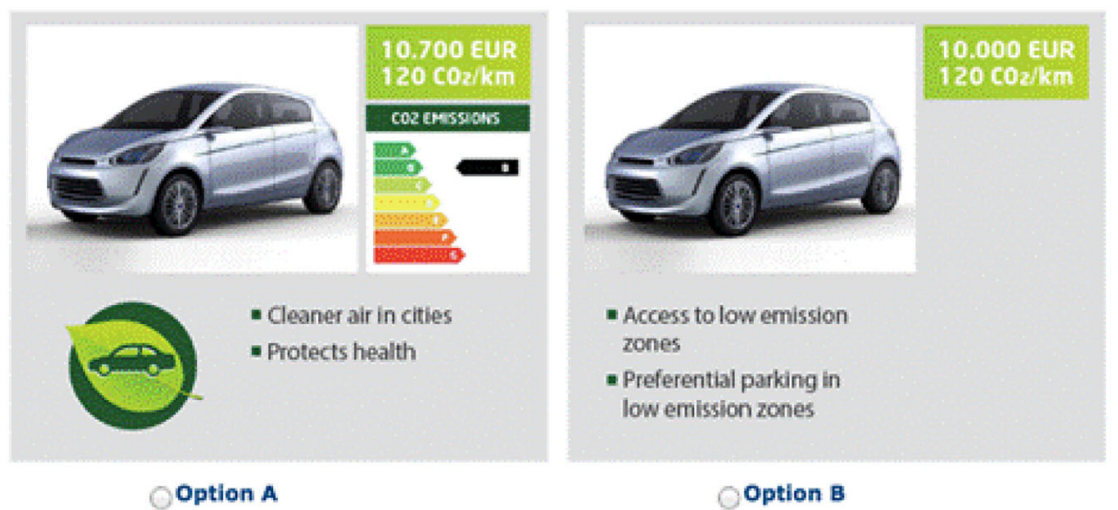

in the experiments $(n=200)$. Gathering the data across countries made it possible to ensure the validity and possibility to generalize findings on awareness, understanding and attitudes regarding the EULES standard as well as the comparison between EULES and $\mathrm{CO}_{2}$ emissions.

\subsection{Survey}

The online survey was designed to explore the level of understanding of, and the attitudes towards, EULES-related issues (Annex 1-Electronic Supplementary Material). The survey questionnaire was structured as follows:

Block A: Self-reported purchase process: Questions assessed self-reported steps and factors that the respondent would take into account in the car purchasing process (class and model, dynamics of purchase process, main attributes considered, information sources).
Block B: Contextual factors: Questions assessing environmental attitudes through consolidated scales, respondents' faith in the eco-behaviours of others and in the effectiveness of their behaviours as consumers, and perceived trade-offs between, for example choosing eco-friendly and performance.

Block C: Questions assessing the awareness of the environmental and health impacts of car usage.

Block D: Questions assessing awareness, trust and the effect of labels.

Block E: Questions assessing socio-demographic profile (e.g. sex, age, possession and usage car).

\subsection{Experiments}

The online experiments were designed to examine the effect of ecolabels on car purchasing. The experiments used the discrete choice methodology to simulate a car purchasing decision and to
Fig. 3 Choice set no. 1 for large car

We would like you to consider the two cars presented below and their characteristics. Which car would you choose?

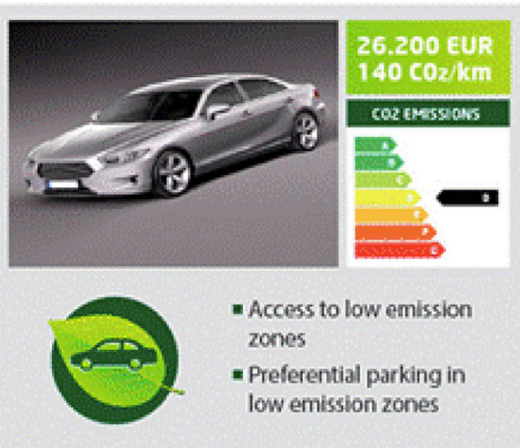

Option A

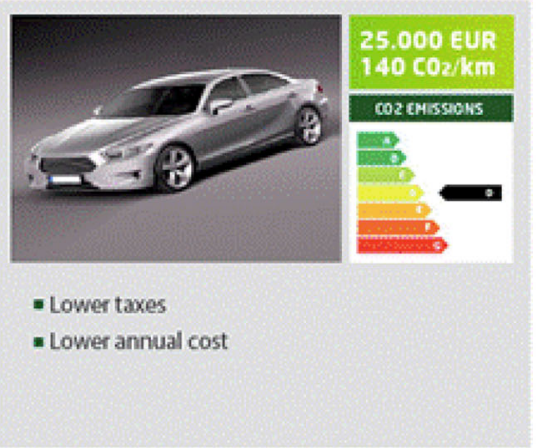

Option B 
Fig. 4 Type of car, by engine

Alternative fuel

Electric

(1)

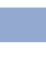

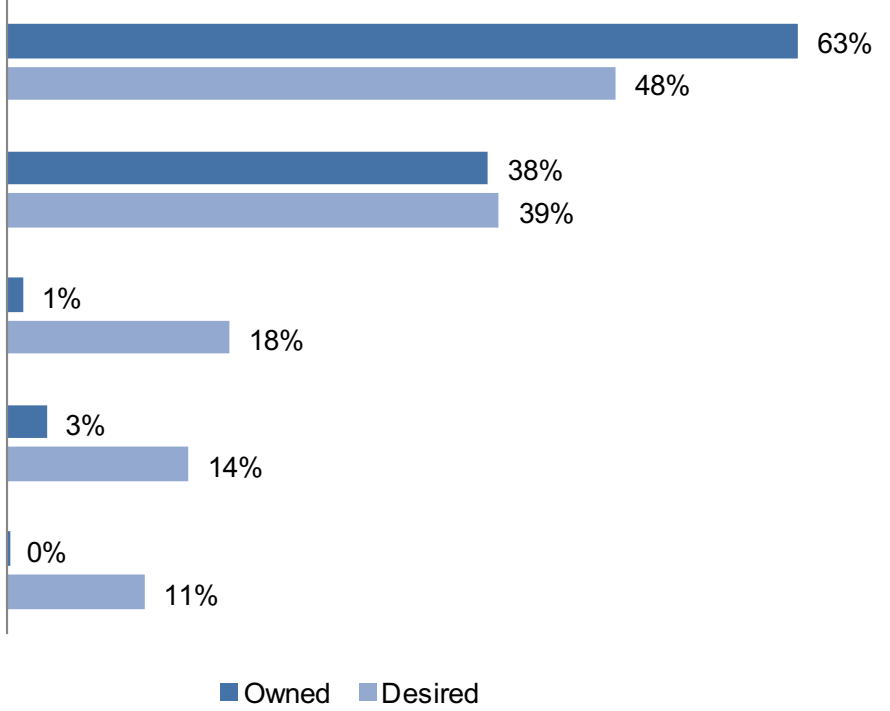

assess the relative impact of different attributes of the cars on respondents' choices. Briefly, it is assumed that when choosing between several cars, consumers consider a range of attributesnumber of seats, engine size, price, etc.- prior to making a purchase. The literature reports that price is the most influential attribute; it dominates other attributes. To assess the relative importance of non-price attributes, in our case an EULES or $\mathrm{CO}_{2}$ label, we offer respondents a series of binary choice between versions of the same model that differ with respect to the presence or absence of environmental information. This is the technique of discrete choice modelling. From a series of choices between cars with different 'environmental profiles', it is possible to estimate whether the presence or absence of a particular attribute increases the probability of choosing a car that features that attribute.

There were two experiments, one featuring small cars and the other large cars. Respondents were shown a picture of two visually identical cars - option A and option B. The two options differed with respect to four attributes or features- the price (baseline or baseline plus a few hundred Euros), the EULES label (present or absent), the EULES message (present or absent) and the $\mathrm{CO}_{2}$ label (present or absent).

The small and large cars differed in terms of prices and the level of $\mathrm{CO}_{2}$ emissions. For the small car, the price was either 10,000 or 10,700 Euros; for the larger car, it was 25,000 or 26,200 Euros. The rationale behind the price differential was the estimated additional cost of introducing the EULES standard that might be passed on to consumers. The small car was associated with a lower level of $\mathrm{CO}_{2}$ emissions (i.e. in the categories $\mathrm{B}$ and $\mathrm{C}$ ) and the large car was associated with a higher level of $\mathrm{CO}_{2}$ emissions (i.e. in the category D). In the experimental design, the label either was present or absent, depending on the choice set.

Figures 2 and 3 below illustrate the choice sets for each car type. In Fig. 2, the respondents had to choose between the small car that had the EULES label and the $\mathrm{CO}_{2}$ label and the same car that had no labels. In Fig. 3, the respondents chose between a large car with the EULES label and without
Fig. 5 Attributes considered in the car purchasing process

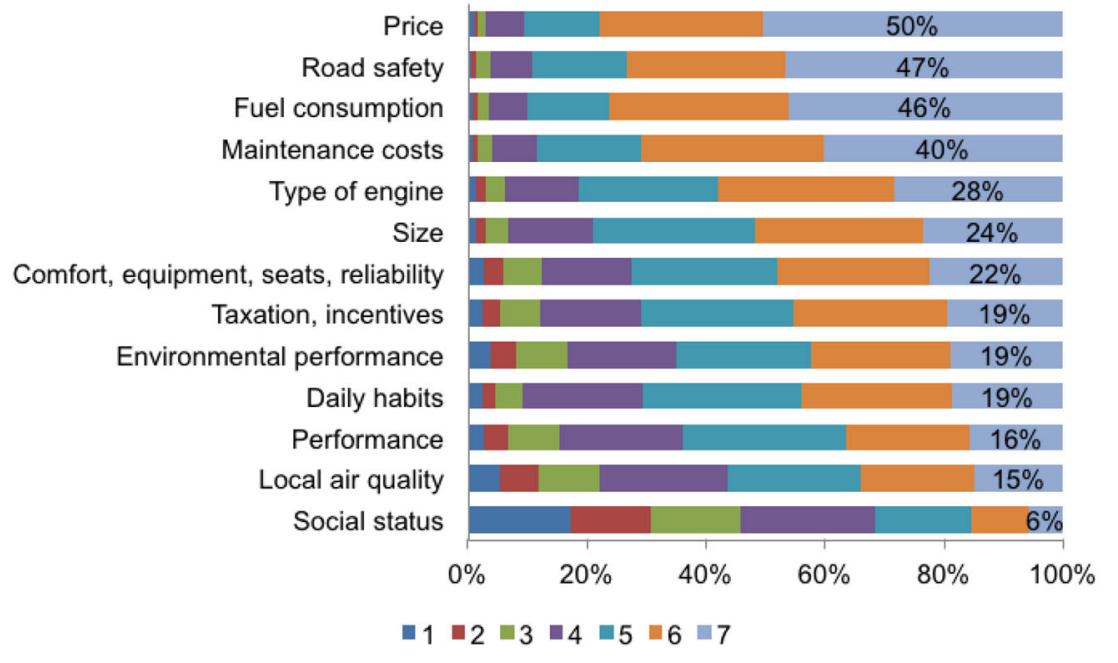


Fig. 6 Assessment of statements related to the car purchase process $(\%)$

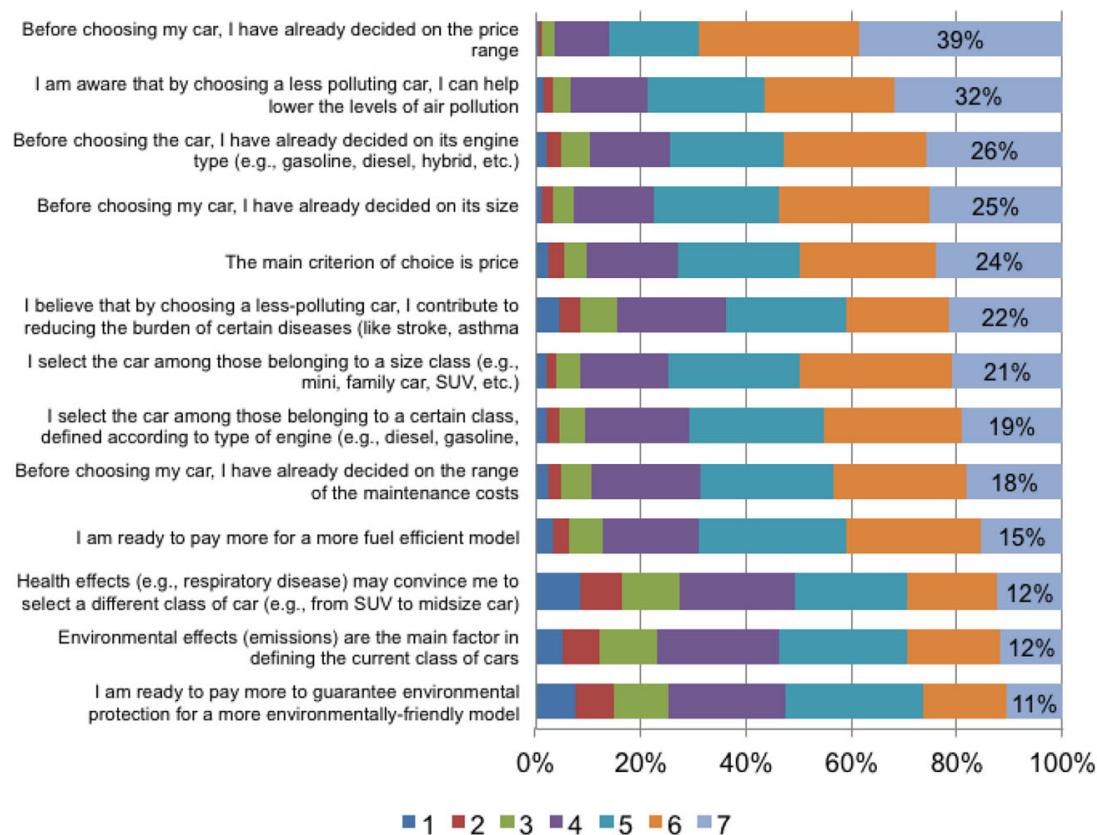

translation of the questionnaire in the other languages, a joint launch took place in the remaining countries.

\section{Results from the survey}

\subsection{Decision-making: describing the purchase process}

In order to gain an indication of the decision-making process behind car purchases, survey respondents were initially asked to report the size of their current car. The most popular car class appears by far to be the small-family car (such as Ford Focus, Volkswagen Golf, Citroën C4) owned by $39 \%$ of respondents. About $19 \%$ of subjects own at least one largefamily car (such as Renault Laguna, Volkswagen Passat or Ford Mondeo). Supermini cars-Peugeot 208, Volkswagen Polo and Renault Clio - come a close third having been selected by $11 \%$ of respondents. In terms of current and future car purchase decisions (Fig. 4), it is worth noting that while

Table 1 Profiles of car purchasers

\begin{tabular}{llll}
\hline Factor & \multicolumn{1}{l}{ Cluster } & \\
\cline { 2 - 3 } & 1. Non-sensitive 57\% $(n=1815)$ & 2. Sensitive 43\% $(n=1385)$ & ANOVA \\
\hline Emphasis on environmental and health issues & -0.22 & 0.29 & $201.52^{*}$ \\
Emphasis on cost & 0.41 & -0.54 & $699.54^{*}$ \\
Emphasis on the present & 0.51 & -0.67 & 0.19 \\
Emphasis on the future & -0.14 & $86.28^{*}$ \\
\hline
\end{tabular}

$* p<0.05$ 
Fig. 7 Present-future attitudes

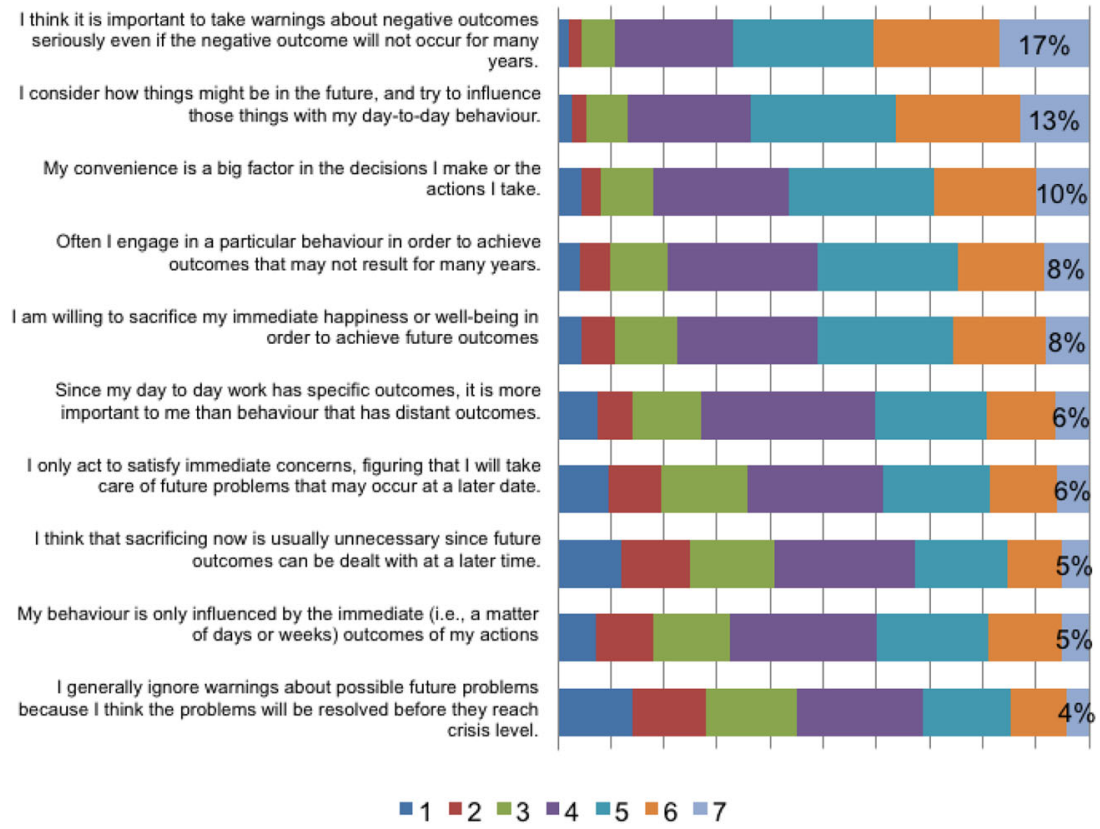

few respondents reported owning environmentally friendly cars, many more said they would buy one in the future. About $18 \%$ of the subjects reported planning to buy a hybrid car. Cars that run on alternative fuels, such as CNG and LPG, were mentioned by $14 \%$ of the respondents (as opposed to $3 \%$ of current owners). About $11 \%$ plan to buy an electric car, currently owned by less than $1 \%$ of current owners.

In terms of car usage, one in two respondents (47\%) reported driver to work on a daily basis. Almost all subjects drive for shopping, although only $10 \%$ do so daily. About $18 \%$ drive their children to and from school every day. Finally, most respondents use their car for weekend getaways (more than 90\%) and holidays (more than $80 \%$ ) at least once a year.

Individuals were then asked to identify what were the main attributes considered during the purchase decision. Respondents were asked to rate each attribute on a 1-7 importance scale, with 7 being 'very important'. As Fig. 5 shows, a car's environmental performance is considered as 'very important' by less than one in five respondents (19\%). Likewise,

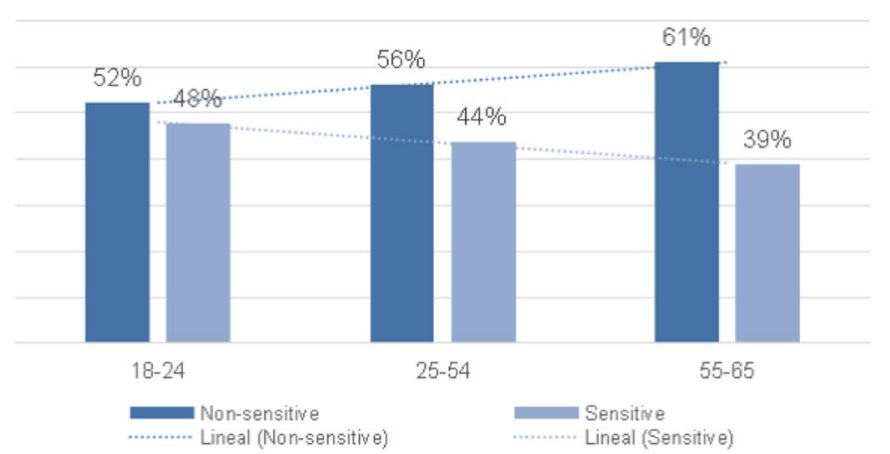

Fig. 8 Profiles of car purchasers, by age group (left) and education (right) local air quality is a very important attribute for only $15 \%$ of respondents. On the other hand, about half of the subjects consider price (50\%), road safety (47\%) and fuel consumption (46\%) followed by maintenance cost $(40 \%)$ and type of engine $(28 \%)$ as very important attributes. After price and road safety, attributes pertaining to the broadly defined 'Fuel Economy' score fairly high in importance.

In addition to car's attributes, individuals were asked to report about the process followed in choosing a car (Fig. 6). From the responses, it can be seen that individuals favour price and its range (24\% and $39 \%$, respectively), along with size and engine (25\% and 26\%, respectively). Environment and health effects are less important. While one third of respondents (32\%) are aware that less polluting cars, ceteris paribus, lower the level of pollution, statements on environmentally friendly attitudes in car purchasing yield very low percentages of full agreement. Health consequences would convince only $12 \%$ of respondents to select a different class of car (e.g. from sport utility vehicle to midsize car). The environmental effects are also not particularly important when

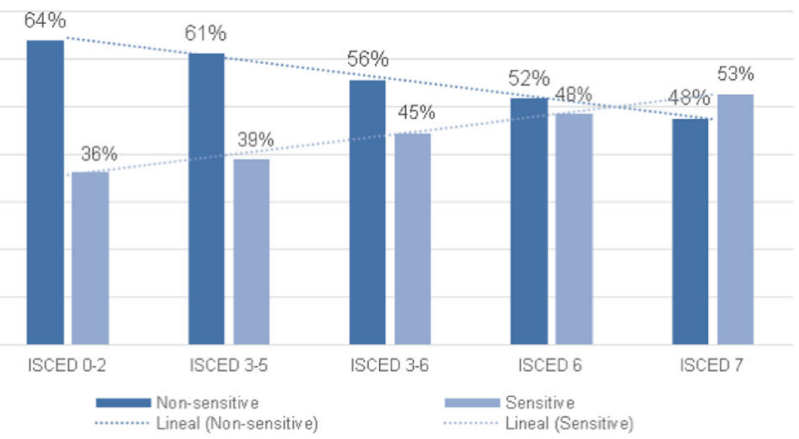


Fig. 9 Profiles of car purchasers by cars' attributed importance (\%)

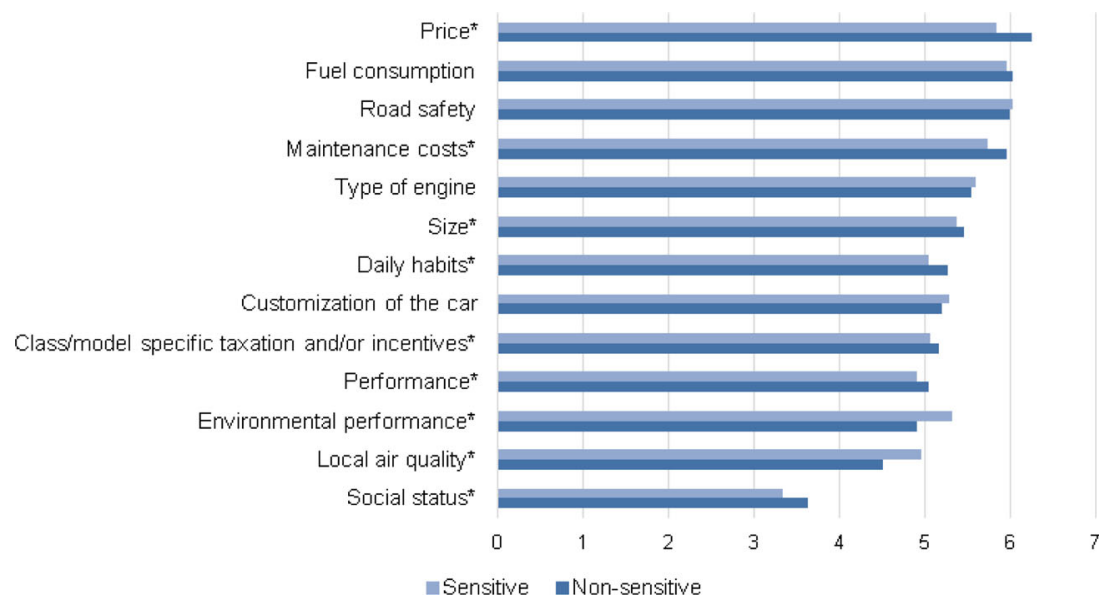

Note: ${ }^{*} p<0.05$ choosing the car's class (12\%). Finally, a mere $11 \%$ of the sample is ready to pay for a more environmentally friendly model.

The responses to the purchase process show that features such as price, type of engine and class of car drive decisions and are likely to have been determined before selecting a particular model. As such, it is likely that environmental and health-related attributes are something of an afterthought. To investigate this further, we can look at answers to questions about respondents' attitudes towards taking current or future consequences into the decision-making process (see Fig. 6).

To examine and summarize these attitudes, a principal component analysis was performed on the questions concerning taking account of the current or future consequences of choices. Two factors emerged: (i) emphasis on the immediate issues $(34.43 \%$ of variance explained) and (ii) a focus on how future impacts on health and the environment affect current behaviour $(25.58 \%$ of variance explained). To develop a typology of consumers' understanding and attitudes towards health and environmental issues in the car purchase process, a cluster analysis of K-means was carried out (Table 1). Cluster 1 consists of respondents who place a greater emphasis on a car's price and maintenance costs, whose behaviour is likely to be influenced by the immediate outcomes of their actions, and who are less likely to sacrifice their current wellbeing for future gains. This group is referred to 'eco-insensitive consumers' (57\% of respondents). The label is used descriptively in order to capture the sense that, for these respondents, environmental and health issues are not important. By contrast, cluster 2 is characterised by a notably different syndrome of attitudes. Here, respondents place a notable emphasis on environmental and health issues. They are more likely to say that they will pay more for an environment-friendly car. They place more emphasis on the future and are more likely to engage in behaviours with long-term outcomes. Members of cluster two are labelled 'eco -sensitive consumers' (43\% of respondents).

Comparing those who score highly on clusters 1 and 2, we find no statistically significant gender differences. However, the ecosensitives are more likely to be younger, highly educated and with a slightly higher self-attributed socioeconomic status than the "ecoinsensitives', see also Fig. 7.

We investigated how these two clusters view the importance given to attributes of cars (see Figs. 8 and 9). As might
Fig. 10 Profiles of car purchasers by next car's engine (\%)

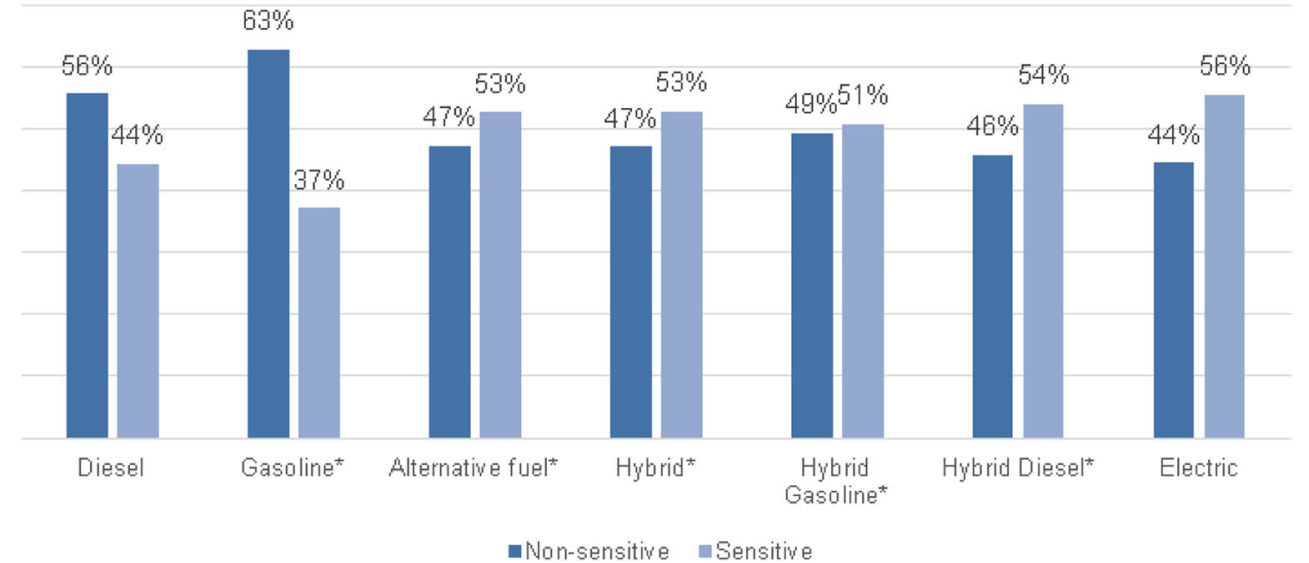


Fig. 11 Contextual factors $(\%)$

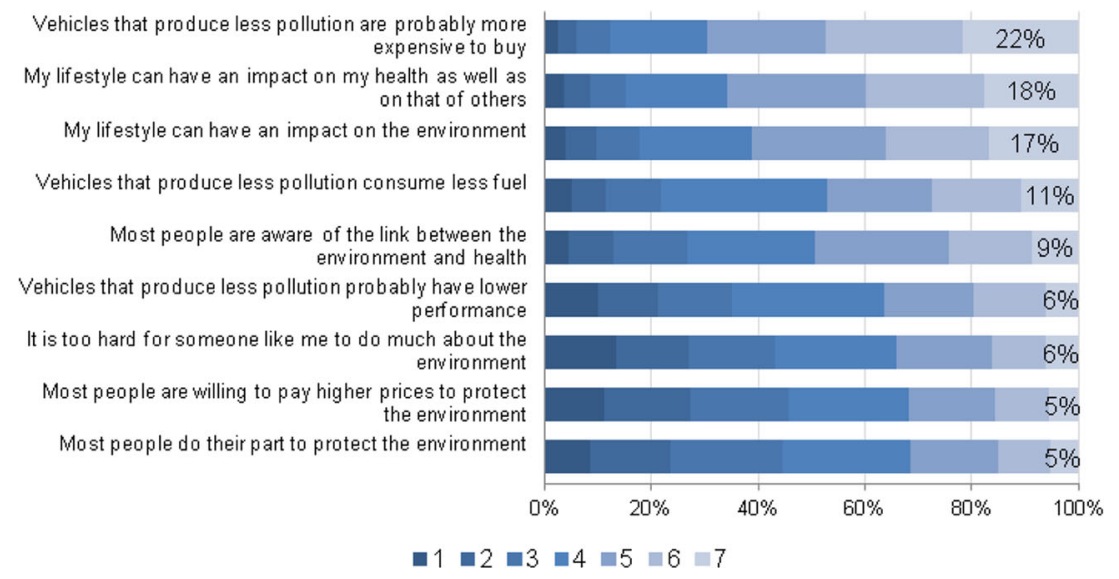

be expected, the 'eco-sensitives' are slightly more oriented towards environmental performance and local air quality than the 'eco-insensitives'. Price, maintenance costs and size are considered slightly less important by the 'eco-sensitives' than the 'eco-insensitives'. This characterization suggests that the post-materials might be in favour of paying a slightly higher price/cost for less polluting cars as they value positively the environmental and health consequences of the car selected.

\subsection{Perceptions and understanding of the health and environmental issues}

Respondents were asked about contextual factors and about their health attitudes and awareness. Only 5\% of respondents agreed that 'most people are willing to pay higher prices to protect the environment' and 'most people do their parts to protect the environment'. This indicates that assumptions about the eco-friendly motivation and commitment of others are low. This may reduce the perceived effectiveness of one's behaviour as a consumer and induce a sense of rationalised apathy — if others are doing nothing, why should I bother?

However, the data shows (see Fig. 10) that lack of faith in others does not prevent $61 \%$ of respondents from agreeing with the statement 'my lifestyle can have an impact on the environment' and $43 \%$ from disagreeing with the statement 'it's hard for someone like me to do much about the environment'. So, despite the lack of faith in others, respondents do not feel that this exempts them from their individual responsibility.

Another constraint to opting for environmentally more sustainable cars is the widespread perception that less polluting and/or lower fuel consumption vehicles are more costly and give poorer performance. We find evidence that many consumers perceive buying eco-friendly car as entailing losses and a sacrifice. Such perceptions suggest that there is not a complete understanding of the connection between $\mathrm{CO}_{2}$ emissions, fuel efficiency, performance and prices.

In this regard, the characterization of the two profiles previously identified reveals that 'non-sensitive consumers' put more responsibility on others ('most people...') than themselves ('my lifestyle...') in comparison with 'sensitive consumers' (see also Fig. 11).

Around 7 out of 10 respondents $(68 \%)$ understand that high pollution emissions could make them ill and 1 in $2(50) \%$ are concerned about how choices today may lead to future health problems. Nevertheless, whereas general awareness about the environmental impact of car usage is fairly high, $43 \%$ of the respondents say they are not worried about getting ill due to
Fig. 12 Profiles of car purchasers by contextual factors $(\%)$

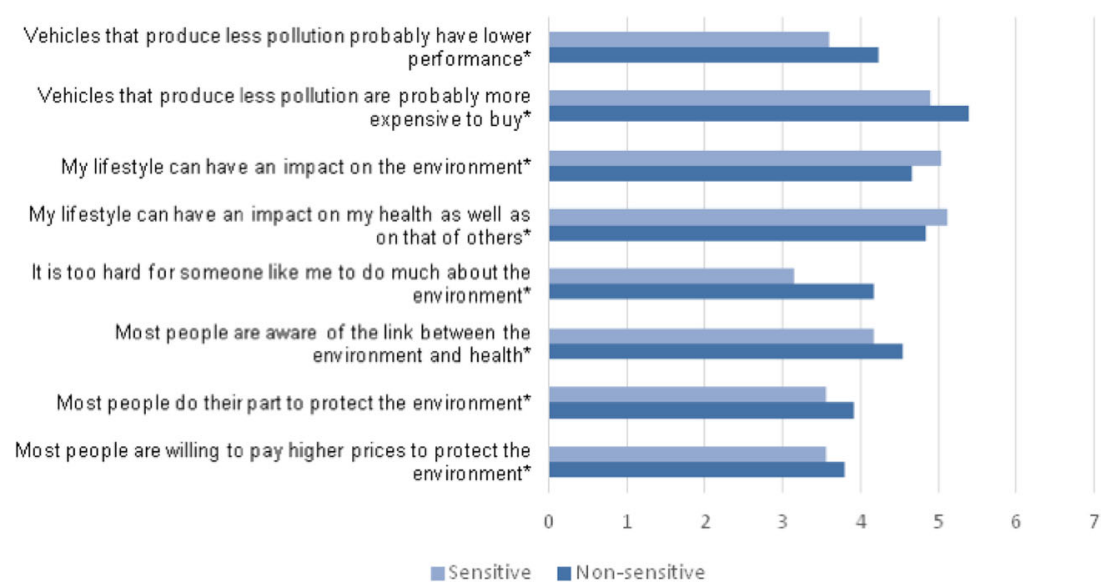


Fig. 13 Health awareness (\%)

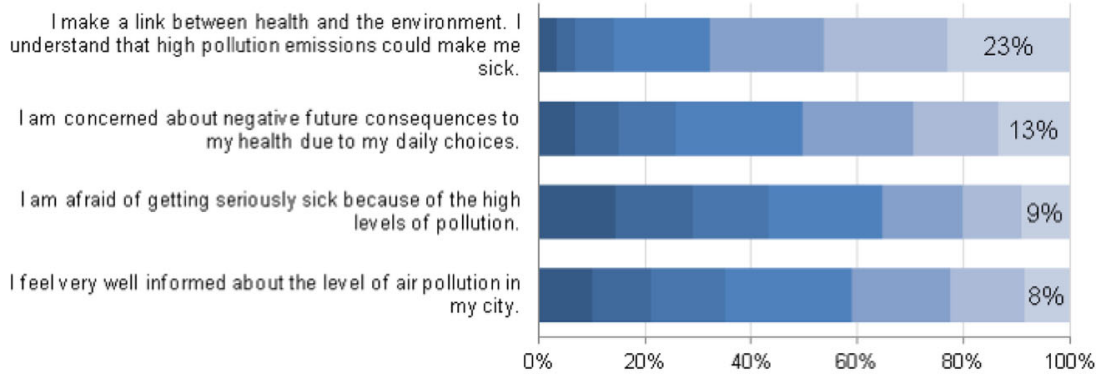

$\square 1=2 \backsim 3 \square 4=5 \square 6=7$

high levels of pollution. Moreover, when asked about information on levels of pollution in their cities, just $8 \%$ said they feel 'well informed' (see also Fig. 12).

Again, the analysis of the profiles reveals slightly different patterns (see Fig. 13). 'Sensitive consumers' are generally more aware than 'non-sensitive consumers' about the health consequences of car usage, even though they stated that they are less well informed about the level of air pollution (Fig. 14).

\subsection{Incentives to influence the purchase process}

Respondents were asked for their opinion on a number of policy-related issues, including incentives for the environmentally friendly choices. Around $30 \%$ of subjects believe that higher financial incentives (such as tax breaks and subsidies) for low-emitting products would be a very effective strategy to tackle air pollution. This policy option ranks second, after 'applying stricter pollution controls on industrial and energy production activities'. The option of requiring the application of best available technology was selected by $38 \%$ of respondents. Overall, while there is support for a range of policies to promote low-emitting vehicles, there is no clear preference for between financial or non-financial incentives. As Fig. 15 shows, around 3 in 10 respondents consider a number of policies as diverse as exemptions for registration and road taxes, schemes for scrapping old vehicles and charging points for electric cars as 'very important'. On the other hand, cheaper parking options and road taxes for low-emitting car owners gain less support ('very important' only by $16 \%$ and $15 \%$, respectively).

Responses to the eight measures were later grouped into the two broader categories of 'financial incentives', which includes tax breaks and subsidies, and 'non-financial incentives', such as access and parking options. Overall respondents tend to consider financial incentives as 'more important' (mean $=5.24$, using a 1-7 importance scale) than nonfinancial incentives $($ mean $=4.71)$.

The impression that priority access and parking options are not as attractive as tax breaks and subsidies finds further support when respondents were asked to react to different nonfinancial incentives. When posed a scenario of a ban on highemitting cars from being used during high pollution days, for example, more people stated that they would switch to public transport, bike or foot ( $23 \%$ of respondents 'totally agree'), rather than buy a low-emitting car (18\%). Likewise, if lowemitting cars got 'substantially cheaper parking places in the city centre', more respondents would rather commute (18\% of full agreement) than buy (14\%). The only scenario where respondents said they would buy a low-emitting car, although by a small margin (20\% 'buy', $19 \%$ 'switch to another mode'), is the introduction of a low-emission zone in the city centre (see Fig. 16).

These results point to the conclusion that non-financial incentives (low-emission zones, driving restrictions, cheap parking fees) might not be effective in moving consumers towards low-emitting cars. However, it may be the case that
Fig. 14 Profiles of car purchasers by health awareness $(\%)$

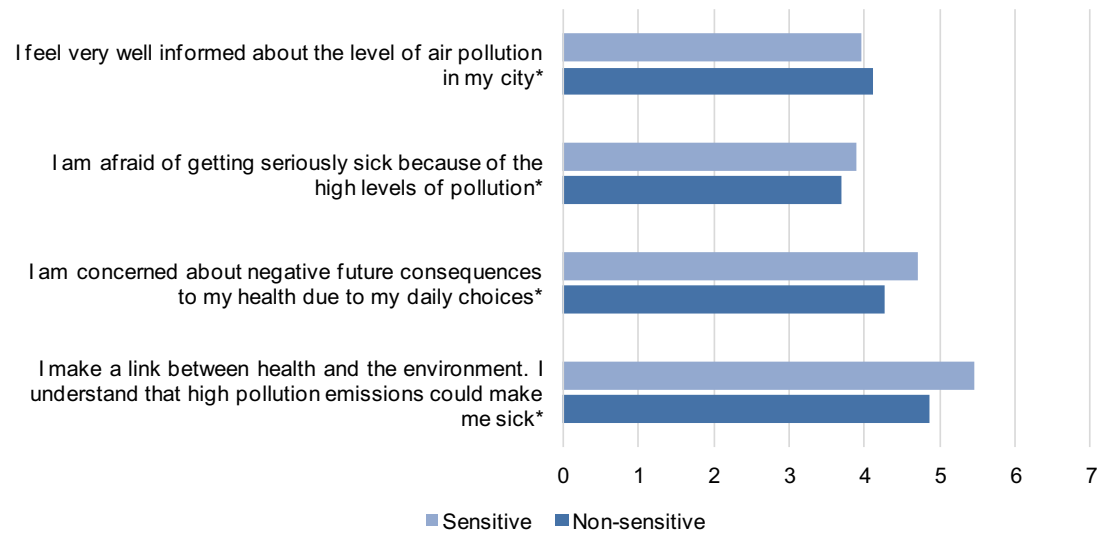


Fig. 15 Strategies to tackle airrelated problems $(\%)$

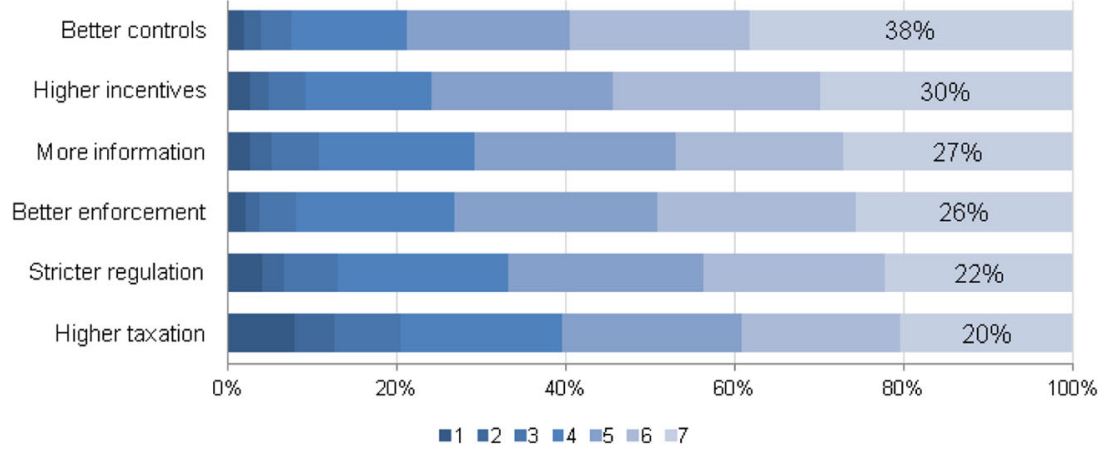

familiarity with car labels. These percentages agreeing (39\%) and disagreeing (37\%) are similar when respondents were asked about the recognition of car labels.

It is notable that percentage of respondents who do not trust the information in car labels (39\%) is higher than for those who trust this information (33\%). However, $38 \%$ of the sample agree with the statement that car labels are a symbol of a product's trustworthiness (27\% disagree) and as many as $37 \%$ believe (agree) that information contained in car labels is truthful and $34 \%$ that the information is sufficient (32\% disagree to both statements). When asked to react to the statement concerning how they use labels when they buy a car, $35 \%$ of the respondents state (agree) that they base their decision upon a (or several) car label (29\% disagree) (Fig. 19).

\section{Results from the experiment}

In the online experiments, respondents were asked to choose between one of two car options. Each option consisted in the picture of the car and additional information. The first experiment featured two versions of the same small car, and the second featured two versions of a large car. Additional information featured a designed combination of one of the two conditions for the four car attributes.
Fig. 16 Respondents who consider 'very important' the following policies

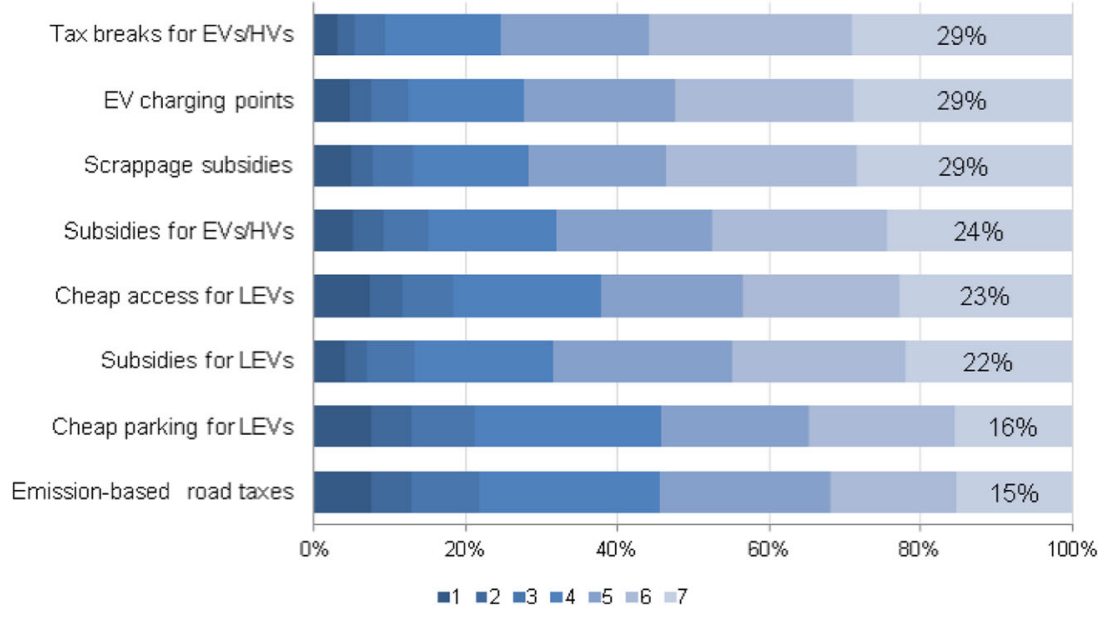


Fig. 17 Respondents' reaction to different incentives
Stop (park outside) $\quad$ Switch (to public transport, bike, foot) $\quad$ Buy low-emitting car

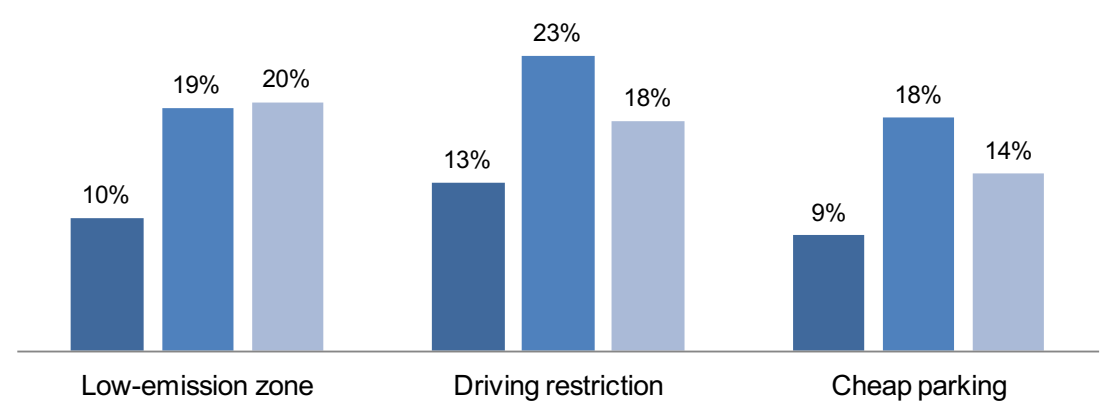

1. The car's base price or with a surcharge to fund ecolabelling (either 10,000 EUR or 10,700 EUR for small cars and either 25,000 EUR or 26,200 EUR for large cars)

2. A label on the car's $\mathrm{CO}_{2}$ emissions (present or absent)

3. A hypothetical EULES label (present or absent)

4. A message on the car's positive features in terms of (i) 'Taxes', i.e. lower costs, (ii) 'Access', i.e. urban accessibility or (iii) 'Health', i.e. health benefits

The experimental data was analysed using a conditional logistic regression to estimate the increase in the probability of selecting a car when each of the attributes described above was added to the car label.

For each of the four attributes, the tables show coefficients, odds ratios, standard errors, $95 \%$ confidence intervals, and the outcome of the effect likelihood ratio tests expressed by the L$\mathrm{R}$ chi-square (the value of the likelihood ratio chi-square statistic for a test of the corresponding effect; DF, the degrees of freedom for the chi-square test Prob $>$ ChiSq, the $p$ value for the chi-square test). We also report the models likelihood, $\mathrm{AICc}$ and $\mathrm{BIC}^{2}$. In discrete choice models, each coefficient is a 'part-worth' estimate or the utility associated with that attribute. In the analysis, the 'Taxes' message was used as a reference point for the categorical variable 'EULES Message' and therefore does not appear in the output tables. 'Taxes' is used as a reference. 'Access' yields a negative part-worth compared to 'Taxes', while 'Health' has a positive part-worth. By default, estimates are based on the Firth bias-corrected maximum likelihood estimators (MLEs) and therefore are considered to be more accurate than MLEs without bias correction.

\footnotetext{
${ }^{2}$ This technique seeks to estimate the parameters of a model, which we denote generically by $(\beta)$, by maximizing the likelihood function. The likelihood function, denoted $L(\beta)$, is the product of the probability density functions (or probability mass functions for discrete distributions) evaluated at the observed data values. Given the observed data, maximum likelihood estimation seeks to find values for the parameters, $\beta$, that maximize $L(\beta)$. Rather than maximize the likelihood function $L(\beta)$, it is more convenient to work with the negative of the natural logarithm of the likelihood function, $-\log L(\beta)$. The problem of maximizing $L(\beta)$ is reformulated as a minimisation problem where you seek to minimize the negative $\log$-likelihood $(-\operatorname{LogLikelihood}=-\log L(\beta)$ ). Therefore, smaller values of the negative log-likelihood or twice the negative log-likelihood (-2LogLikelihood) indicate better model fits.
}

The result of the statistical analysis for the two experiments shows that all four attributes considered have a significant impact $(P<0.05)$ on the participants' choices (see Tables 2 and 3). The presence of logos, either EULES or on $\mathrm{CO}_{2}$ emissions, has a small negative effect, $12 \%$ less likely for both logos for small cars and $7 \%$ (EULES) and $6 \%\left(\mathrm{CO}_{2}\right)$ for large cars. For small and large cars, the additional price had a marginal positive effect in terms of increasing probabilities of selection by respondents (17\% for small cars and 38\% for large cars). The effect of the added messages is slightly positive in the case of 'health', increasing odds of selection of $13 \%$ for small cars and $11 \%$ for large cars while negative for 'access', decreasing odds of selection by $50 \%$ for small cars and $40 \%$ for large cars.

Of significance is the finding that the single most important predictor affecting choices is the message conveying the benefits of a low-emission car that accompany the logo. Tables 4 and 5 show how the different benefits captured in the messages (taxes, urban access and health) impact on choices.

Table 5, focusing on larger cars, is based on the same analysis as Table 1 . The odds ratio was 2.48 versus urban access and 1.34 versus health benefits. This means that information about the tax advantages of low-emission cars makes the choice of selection 1.48 times more likely than the urban access benefit and 0.30 more likely than a health benefit.

Overall, this shows that information attached to a lowemission logo is the most important attribute in in increasing the likelihood of choice. But, crucially a message about tax advantages has considerably more impact than messages about the benefits of urban access and health. This effect is particularly strong for those choosing small cars and to a lesser extent for those choosing large cars.

\section{Discussion}

In order to comply to the Paris Agreement (UNFCCC 2018), greenhouse gas emissions have to reduce significantly. Current levels of air pollution are above international agreements and an important factor that contributes to air pollution is road transportation (Davis et al. 2010; EEA 2015). It is 
Fig. 18 Respondents' reaction to different incentives
Non-commuters only
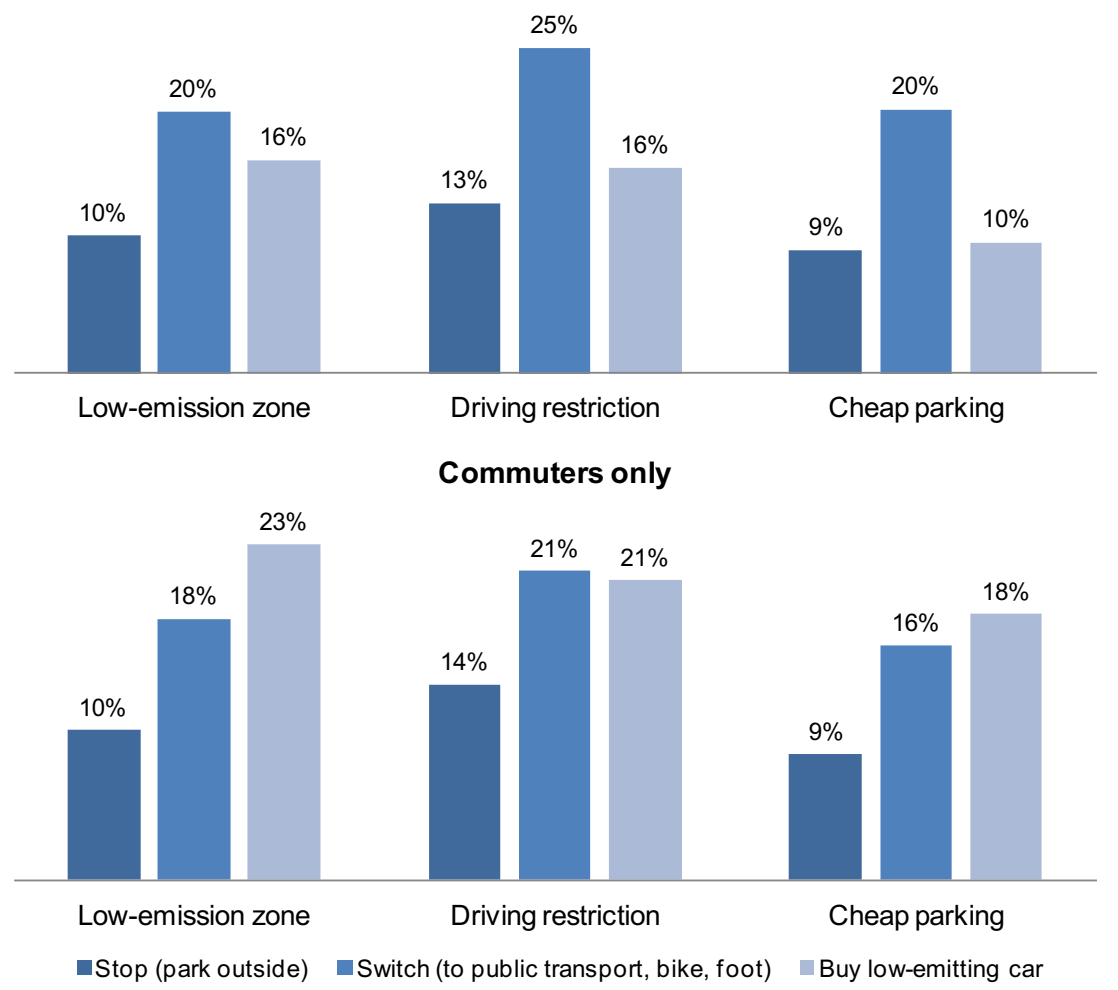

therefore of great importance to examine effectiveness of behavioural techniques that might improve consumers' choices when buying cars. The main objectives of the current study were (1) to assess and explore public responses and the role of public authorities to a EULES in order to deliver real-world emission levels below the most stringent current emission limits and to (2) experimentally test the incentives for this optimization.

First, as the results from the survey show, Europeans are aware of the health and environmental impact of cars. The survey points to a general understanding of the adverse health effects of pollution. Results showed that the respondents recognize that there is a link between the environmental protection and human health. Second, people think that the pollution in their cities or neighbourhoods is rather high. Third, the result also shows respondents are aware of the environmental impact of polluting vehicles. More than half of respondents (54\%) believe that 'cars contribute significantly to the air pollution' in their city or neighbourhood. Despite the high environmental awareness, the main factor that subjects take into account when buying a car is price (50\% of respondents), followed by road safety (48\%) and fuel consumption (46\%). Most importantly, only 1 in $10(11 \%)$ is ready to pay more for a more environment-friendly car. Finally, results also confirm the gap between self-reported attitudes/intentions and actual behaviours: health and environmental concerns come only after many other attributes (price, safety, performance, etc.) in terms of importance in influencing car purchase decisions.
Fig. 19 Existing awareness and perception on car labels

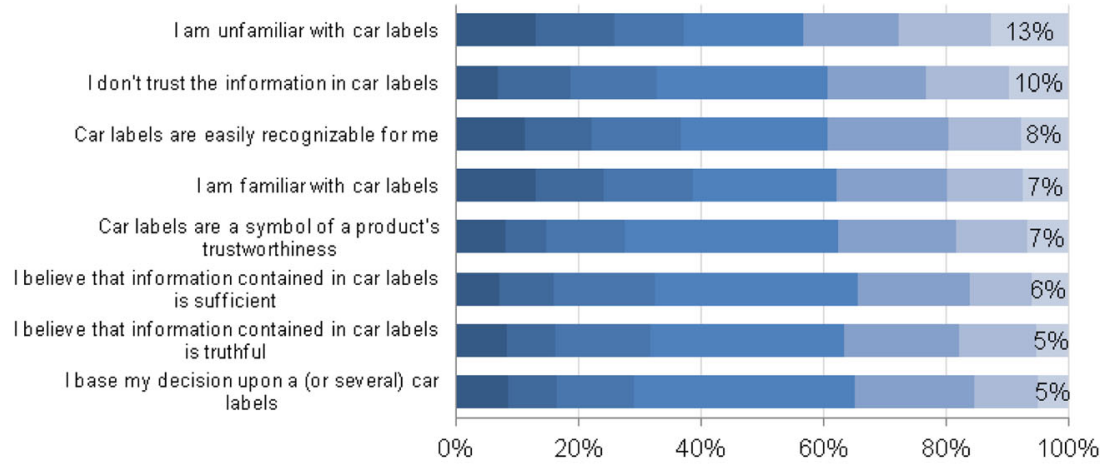

$\square 1 \square 2 \square 3 \square 4 \square 5 \square 6 \square 7$ 
Table 2 Parameter estimates SMALL CARS

\begin{tabular}{|c|c|c|c|c|c|c|c|c|}
\hline Term & Estimate & Odds ratios & Std error & Lower $95 \%$ & Upper 95\% & L-R chi-square & $D F$ & Prob $>$ ChiSq \\
\hline Price & 0.17 & 1.1752 & 0.00 & 0.00 & 0.00 & 251.796 & 1 & $<0.0001 *$ \\
\hline EULES Message Access & -0.65 & 0.5219 & 0.01 & -0.68 & -0.62 & 2169.130 & 2 & $<0.0001^{*}$ \\
\hline EULES Message Health & 0.12 & 1.1287 & 0.01 & 0.09 & 0.15 & & & $<0.0001^{*}$ \\
\hline Absence of EULES Logo & -0.13 & 0.8779 & 0.01 & -0.15 & -0.11 & 167.296 & 1 & $<0.0001 *$ \\
\hline $\mathrm{CO}_{2} \operatorname{Logo}\left[\mathrm{NO}_{-} \mathrm{CO}_{2} \mathrm{~L}\right]$ & -0.13 & 0.8764 & 0.01 & -0.15 & -0.11 & 203.018 & 1 & $<0.0001 *$ \\
\hline
\end{tabular}

$* p<0.05$

In fact, many consumers perceive buying an eco-friendly car as entailing a loss/sacrifice in terms of performance. There is a quite widespread perception that less polluting or lower consumption vehicles are associated with higher prices and that, to some extent, also compromise performance, which is in line with previous research (Gould and Golob 1998; Zhang et al. 2015). In this regard, citizens do not clearly understand the difference between air pollution and greenhouse gas emissions. Nearly half of the respondents (47\%) agree with the statement 'Vehicles that produce less pollution consume less fuel'. Financial incentives are the most likely to change consumers' behaviour towards low-emission cars. According to $30 \%$ of survey respondents, providing higher financial incentives for low-emission products would be an effective strategy to tackle air pollution. Financial measures (tax breaks, subsidies) are more likely to nudge consumers towards low-emission cars than are non-financial incentives. Among the latter, low-emission zones seem more appealing, especially for those consumers who drive to work on a daily basis. Citizens are likely to prefer tax exemptions and subsidies rather than environmental taxes or road pricing. We draw this conclusion from the survey, in which respondents believe they are paying already too much of environmental taxes for their car and are not in favour of applying 'road pricing' (e.g. road tax, registration tax) for major metropolitan areas (e.g. cities with over 100,000 inhabitants and their suburbs). At the same time, they welcome proposals in which the government would provide either tax exemptions or subsidies for those purchasing a low-emitting car. European consumers are not too acquainted with car labels. More than $43 \%$ of respondents admit to be 'unfamiliar with' existing car labels. Around 37\% disagree with the statement that labels are 'easily recognizable'. As many as $39 \%$ do not trust the information displayed, and reportedly, the most common use of labels is 'to check if what said in the advertisement is true'. Many even misunderstand their purpose: nearly $38 \%$ believes that labels symbolize a product's reliability. In any case, the element of car labels that most attracts the attention of candidate buyers is the message.

To find that out, we ran a series of experiments in which individuals were asked to choose a car between two options. Each option consisted in a label depicting a car and a series of additional elements-logos, price tags and a series of messages. As the results show, all attributes are significant, and they all contribute to the choice. However, the strongest utility is given by the messages. Respondents were more likely to choose EULES-friendly cars when they the label shows information on lower costs or lower taxes. When it comes down to one car purchase decision, consumers are less interested in knowing about health-related benefits, convenient parking or access fees. A minor increase in price has a negligible effect. Finally, combinations of one message with other elementsEULES logo, $\mathrm{CO}_{2}$ logo or both - within the same label have a small but positive effect on participants' choices.

Ecolabelling is considered an effective strategy to encourage future consumers towards forms of sustainable consumption (Thøgersen et al. 2010). Compared to the more general literature on ecolabels and especially to that focusing on white goods and food, the study of car labelling is considerably less

Table 3 Parameter estimates - large cars

\begin{tabular}{|c|c|c|c|c|c|c|c|c|}
\hline Term & Estimate & $\begin{array}{l}\text { Odds } \\
\text { ratios }\end{array}$ & $\begin{array}{l}\text { Std } \\
\text { error }\end{array}$ & $\begin{array}{l}\text { Lower } \\
95 \%\end{array}$ & $\begin{array}{l}\text { Upper } \\
95 \%\end{array}$ & L-R chi-square & $D F$ & Prob $>$ ChiSq \\
\hline Price & 0.32 & 1.3858 & 0.00 & 0.00 & 0.00 & 1286.676 & 1 & $<0.0001 *$ \\
\hline EULES_Message[Access] & -0.51 & 0.6019 & 0.01 & -0.53 & -0.48 & 1555.362 & 2 & $<0.0001 *$ \\
\hline EULES_Message[Health] & 0.11 & 1.1114 & 0.01 & 0.08 & 0.14 & & & $<0.0001 *$ \\
\hline EULES_Logo[NO_EULES_L] & -0.08 & 0.9231 & 0.01 & -0.10 & -0.06 & 73.718 & 1 & $<0.0001 *$ \\
\hline $\mathrm{CO}_{2 \_} \mathrm{Logo}\left[\mathrm{NO} \mathrm{CO}_{2 \_} \mathrm{L}\right]$ & -0.06 & 0.9436 & 0.01 & -0.08 & -0.04 & 39.794 & 1 & $<.0001 *$ \\
\hline
\end{tabular}

AICc 18,949.468, BIC 18987.866, $-2 \times$ Loglikelihood = 18,939.464, $-2 \times$ Firth LogLikelihood $=18,894.23$

$* P<0.05$ 
Table 4 Small cars: messages and odds ratio comparison

\begin{tabular}{|c|c|c|c|c|c|}
\hline Compared 1 & Compared 2 & Probability 1 & Probability 2 & Odds ratio 1 & Odds ratio 2 \\
\hline EULES_Message=Access & EULES_Message=Health & 0.312 & 0.68 & 0.46 & 2.16 \\
\hline EULES_Message=Access & EULES_Message=Taxes & 0.24 & 0.76 & 0.31 & 3.25 \\
\hline EULES_Message=Health & EULES_Message=Access & 0.68 & 0.32 & 2.16 & 0.46 \\
\hline EULES_Message=Health & EULES_Message=Taxes & 0.40 & 0.60 & 0.67 & 1.50 \\
\hline EULES_Message $=$ Taxes & EULES_Message=Access & 0.76 & 0.24 & 3.25 & 0.31 \\
\hline EULES_Message=Taxes & EULES_Message=Health & 0.60 & 0.40 & 1.50 & 0.67 \\
\hline
\end{tabular}

developed with only a limited amount of studies conducted to examine its effects (Choo and Mokhtarian 2004; Kurani and Turrentine 2002; Lane and Potter 2007; Loureiro et al. 2012; Noblet et al. 2006; Teisl et al. 2008; Teisl and Roe 2005). The first strength of the current study is that it established which factors are associated with the effectiveness of labelling cars. Ecolabels are considered as voluntary environmental and consumer policy instruments and therefore considered as a pragmatic option for policy developers. It is a form of choice architecture that does not affect the perceived autonomy of consumers, being an ideal example of a 'nudge'. The second strength of the study is that we are the first that experimentally examined causal effects on consumption choices. Until now, there has been no experimental study conducted on the effects of car labels on consumers' decision-making, although it is of great importance to reduce the negative health consequences of road transport (EEA 2015). Teisl et al. (2008) showed that it is important to test a model linking individual characteristics and label characteristics in order to create effective ecolabels that affect individuals' perceptions of the eco-friendliness of products. Existing studies on ecolabels have been focusing on the relationship between individual characteristics and ecobehaviour or between label characteristics and eco-behaviour but not on the interaction between these two factors. It is therefore important to extend this knowledge by examining both individual characteristics and the manipulation of ecolabels simultaneously and test the effectiveness of the ecolabels. As Teisl et al. (2008) already have shown, it is highly relevant to examine underlying psychological factors and individuals' priors of the product and of the environmental problem, because it plays a strong role for the long-run provision of eco-information, in particular in context where individual consumers hold incorrect perceptions.

One limitation of the current study is that participants conducted the survey and experiment online, whereby we did not control the situation in which they participated. This is a potential harm of internal validity. However, it could also be argued that such settings could reflect the real purchasing decisions to a larger extent. One could imagine that a typical consumer usually chooses its vehicle on the basis of a number of attributes by browsing the Internet, and subsequently, the person visits a car dealer to obtain further details. Additionally, future research could investigate the effects of ecolabels on consumption behaviour in real-life car shops. Secondly, only a limited amount of car types were used in the experiments so it is difficult to generalize the results to other type of cars. Nonetheless, the same mechanism that we have found in the current study seems to be applicable to other cars as well, in particular because we assessed public responses to possible incentives in general that might affect the perception of the ecolabels.

\section{Conclusions}

The current study is of great importance because it will provide the standard that could be presented to consumers either in a form of a label, a message or both. In this study, our research goal was to identify and test the elements which would nudge consumers towards an environmentally and health-friendly EULES car. Our findings will support

Table 5 Large cars: messages and odds ratio comparison

\begin{tabular}{|c|c|c|c|c|c|}
\hline Compared 1 & Compared 2 & Probability 1 & Probability 2 & Odds ratio 1 & Odds ratio 2 \\
\hline EULES_Message=Access & EULES_Message=Health & 0.35 & 0.65 & 0.541 & 1.85 \\
\hline EULES_Message=Access & EULES_Message=Taxes & 0.29 & 0.71 & 0.40 & 2.48 \\
\hline EULES_Message=Health & EULES_Message=Access & 0.65 & 0.35 & 1.85 & 0.54 \\
\hline EULES_Message=Health & EULES_Message=Taxes & 0.43 & 0.57 & 0.74 & 1.34 \\
\hline EULES_Message=Taxes & EULES_Message=Access & 0.71 & 0.29 & 2.48 & 0.40 \\
\hline EULES_Message=Taxes & EULES_Message=Health & 0.57 & 0.43 & 1.34 & 0.74 \\
\hline
\end{tabular}


governmental decision-making process with respect to the EULES format that should have the greatest impact on consumer purchasing decisions. In addition, we also assessed the likely consumers' preference between the $\mathrm{CO}_{2}$ label and the EULES label. The results will help to guide environmental conscious customers towards the purchase of vehicles with clean emission profiles. Furthermore, it will provide a benchmark for local or national authorities when developing financial or access and demand policies to promote clean transportation. Finally, it will provide an incentive for manufacturers to produce vehicles that deliver significant emission reductions on the road.

Acknowledgements F. Folkvord, G. Veltri, F. Lupiáñez-Villanueva, P. Tornese and C. Codagnone developed the study concept and contributed to the study design. G. Veltri, F. Lupiáñez-Villanueva, P. Tornese and C. Codagnone collected, tested and analysed the data. F. Folkvord interpreted the data under supervision of $\mathrm{F}$. Lupiáñez-Villanueva, C. Codagnone, F. Bogliacino, G. Veltri and G. Gaskell. F. Folkvord drafted the manuscript. G. Veltri, F. Lupiáñez-Villanueva, P. Tornese, C. Codagnone and G. Gaskell provided critical revisions. All authors approved the final version of the manuscript for submission.

This study has been funded by the European Commission (No. ENV.C.3/FRA/2013/0013, Service No. 8, EC DG ENV). The content of this study represents the views of the authors and is its sole responsibility; it can in no way be taken to reflect the views of the European Commission and/or CHAFEA or any other body of the European Union. The European Commission and/or CHAFEA do not guarantee the accuracy of the data included in this report nor do they accept responsibility for any use made by third parties thereof.

Open Access This article is distributed under the terms of the Creative Commons Attribution 4.0 International License (http:// creativecommons.org/licenses/by/4.0/), which permits unrestricted use, distribution, and reproduction in any medium, provided you give appropriate credit to the original author(s) and the source, provide a link to the Creative Commons license, and indicate if changes were made.

\section{References}

Achtnicht M (2012) German car buyers' willingness to pay to reduce CO2 emissions. Climate Change 113(3-4):679-697

Bamberg S (2003) How does environmental concern influence specific environmentally related behaviors? A new answer to an old question. J Environ Psychol 23(1):21-32

Berger IE, Corbin RM (1992) Perceived consumer effectiveness and faith in others as moderators of environmentally responsible behaviors. $\mathrm{J}$ Public Policy:79-89

Bougherara D, Grolleau G, Thiébaut L (2005) Can labelling policies do more harm than good? An analysis applied to environmental labelling schemes. Eur JL \& Econ 19(1):5-16

Choo S, Mokhtarian PL (2004) What type of vehicle do people drive? The role of attitude and lifestyle in influencing vehicle type choice. Transp Res Part A: Pol Prac 38(3):201-222

Codagnone C, Bogliacino F, Veltri G (2013) Testing CO2/car labelling options and consumer information. Final Report. Brussels: European Commission (http://ec.europa. eu/clima/policies/transport/vehicles/labelling/docs/report_car_labelling_en. pdf)
Codagnone C, Veltri GA, Bogliacino F, Lupiáñez-Villanueva F, Gaskell G, Ivchenko A, Mureddu F (2016) Labels as nudges? An experimental study of car eco-labels. Econ Polit 33(3):403-432

COWI (2002) Fiscal measures to reduce $\mathrm{CO}_{2}$ emissions from new passenger cars. COWI Environmental consultants, final report under a contract to European Commission, DG Environment

Davis SJ, Caldeira K, Matthews HD (2010) Future CO2 emissions and climate change from existing energy infrastructure. Science 329(5997):1330-1333

European Environment Agency (EEA) (2015) Air quality in Europe2015 report (available at https:/www.eea.europa.eu/publications/ air-quality-in-europe-2015. Retrieved at 23-05-2018)

Gadenne D, Sharma B, Kerr D, Smith T (2011) The influence of consumers' environmental beliefs and attitudes on energy saving behaviours. Energy Policy 39(12):7684-7694

Gayer T, Viscusi WK (2013) Overriding consumer preferences with energy regulations. J Regul Econ 43(3):248-264

Gould J, Golob TF (1998) Clean air forever? A longitudinal analysis of opinions about air pollution and electric vehicles. Transp Res D: Transp Environ 3(3):157-169

Grunert KG, Wills JM (2007) A review of European research on consumer response to nutrition information on food labels. J Public Health 15(5):385-399

Heinzle SL, Wüstenhagen R (2012) Dynamic adjustment of eco-labeling schemes and consumer choice - the revision of the EU energy label as a missed opportunity? BSE 21(1):60-70

Johnson EJ, Shu SB, Dellaert BG, Fox C, Goldstein DG, Häubl G, Wansink B (2012) Beyond nudges: tools of a choice architecture. Mark Lett 23(2):487-504

Kosters M, Van der Heijden J (2015) From mechanism to virtue: evaluating nudge theory. Evaluation 21(3):276-291

Kurani TS, Turrentine TS (2002) Marketing clean and efficient vehicles: a review of social marketing and social science approaches. Institute of Transportation Studies: University of California at Davis

Kushwaha GS, Sharma NK (2016) Green initiatives: a step towards sustainable development and firm's performance in the automobile industry. J Clean Prod 121:116-129

Lane B, Potter S (2007) The adoption of cleaner vehicles in the UK: exploring the consumer attitude-action gap. J Clean Prod 15(1112): $1085-1092$

Loureiro SM, Sardinha IMD, Reijnders L (2012) The effect of corporate social responsibility on consumer satisfaction and perceived value: the case of the automobile industry sector in Portugal. J Clean Prod $37: 172-178$

Noblet CL, Teisl MF, Rubin J (2006) Factors affecting consumer assessment of eco-labeled vehicles. Transp Res D: Transp Environ 11(6): $422-431$

Ntziachristos L, Papadimitriou G, Ligterink N, Hausberger S (2016) Implications of diesel emissions control failures to emission factors and road transport NOx evolution. Atmos Environ 141:542-551

Ölander F, Thøgersen J (2014) Informing versus nudging in environmental policy. J Clean Prod 37(3):341-356

Peters E, Dieckmann NF, Västfjäll D, Mertz CK, Slovic P, Hibbard JH (2009) Bringing meaning to numbers: the impact of evaluative categories on decisions. J Exp Psychol Appl 15(3):213-227

Petty RE, Cacioppo JT (1986) The elaboration likelihood model of persuasion. In: Communication and persuasion. Springer, New York, NY, pp 1-24

Sahoo A, Sawe N (2015) The heterogeneous effects of eco-labels on internalities and externalities. Stanford University, Graduate School of Business

Song L, Lim Y, Chang P, Guo Y, Zhang M, Wang X, Cai H (2019) Ecolabel's role in informing sustainable consumption: a naturalistic decision making study using eye tracking glasses. J Clean Prod 218: 685-695 
Teisl MF (2003) What we may have is a failure to communicate*: labeling environmentally certified forest products. Forest Science 49(5): 668-680

Teisl MF, Garner L, Roe B, Vayda ME (2003) Labeling genetically modified foods: how do US consumers want to see it done. AgBioForum 6(1\&2):48-54

Teisl MF, Rubin J, Noblet CL (2008) Non-dirty dancing? Interactions between eco-labels and consumers. J Econ Psych 29(2):140-159

Teisl MF, Roe B (2005) Evaluating the factors that impact the effectiveness of eco-labelling programmes. In: Krarup S, Russel CS (eds) Environment, information and consumer behaviour, Edward Elgar Publishing Limited, Cheltenham UK, pp 65-90

Thøgersen J (2000) Psychological determinants of paying attention to eco-labels in purchase decisions: model development and multinational validation. J Clean Prod 23(3):285-313

Thøgersen J (2002) Eco-labeling is one among a number of policy tools that are used in what. In: Dietz, Stern PC (ed) $1^{\text {st }}$ edn. New tools for environmental protection: education, information, and voluntary measures. pp 83-105

Thøgersen J (2005) How may consumer policy empower consumers for sustainable lifestyles? J Clean Prod 28(2):143-177

Thøgersen J, Haugaard P, Olesen A (2010) Consumer responses to ecolabels. Eur J Mark 44(11/12):1787-1810

Thøgersen J, Jørgensen AK, Sandager S (2012) Consumer decision making regarding a "green" everyday product. Psychol Market 29(4): $187-197$
Thøgersen J, Noblet C (2012) Does green consumerism increase the acceptance of wind power? Energy Policy 51:854-862

United Nations Framework Convention on Climate Change (NFCCC) (2017) UN Climate Change Annual Report 2017 (available at: https://unfecc.int/annualreport). Retrieved at 23-05-2018

United Nations Framework Convention on Climate Change (NFCCC) (2018) Available at: https://unfccc.int/process/the-paris-agreement/ status-of-ratification. Retrieved at: 23-05-2018

Woodcock J, Edwards P, Tonne C, Armstrong BG, Ashiru O, Banister D, Franco OH (2009) Public health benefits of strategies to reduce greenhouse-gas emissions: urban land transport. The Lancet 374(9705):1930-1943

World Health Organization (WHO) (2018) http://www.who.int/newsroom/detail/02-05-2018-9-out-of-10-people-worldwide-breathepolluted-air-but-more-countries-are-taking-action

Zhang Y, Wang H, Liang S, Xu M, Zhang Q, Zhao H, Bi J (2015) A dual strategy for controlling energy consumption and air pollution in China's metropolis of Beijing. Energy 81:294-303

Publisher's note Springer Nature remains neutral with regard to jurisdictional claims in published maps and institutional affiliations. 